University of South Florida

DIGITAL COMMONS

Digital Commons @ University of

@ UNIVERSITY OF SOUTH FLORIDA

South Florida

QMaSC: A Handbook for Directors of

Quantitative and Mathematics Support Centers

USF Libraries

$1-1-2016$

\title{
13. Staffing and Hiring
}

Christine Tinsley

University of Oklahoma

Follow this and additional works at: https://digitalcommons.usf.edu/qmasc_handbook

\section{Recommended Citation}

Christine Tinsley (2016), "Staffing and Hiring", http://dx.doi.org/10.5038/9780977674435.ch13 in G. Coulombe, M. O'Neill, M. Schuckers (Eds.) A Handbook for Directors of Quantitative and Mathematical Support Centers, Neck Quill Press, http://scholarcommons.usf.edu/qmasc_handbook.

This Staffing, Hiring, and Training is brought to you for free and open access by the USF Libraries at Digital Commons @ University of South Florida. It has been accepted for inclusion in QMaSC: A Handbook for Directors of Quantitative and Mathematics Support Centers by an authorized administrator of Digital Commons @ University of South Florida. For more information, please contact digitalcommons@usf.edu. 


\section{Staffing and Hiring}

(c) Christine Tinsley,

University of Oklahoma

吅

\section{Introduction}

Some QMaSCs may have just a few employees, while others may have 50 or more employees, depending on the needs and budgets of each institution. No matter the size of the QMaSC, a good, qualified staff is the most important asset. A larger center may have a director, assistant director, course coordinators, and a tutoring staff, whereas a smaller center may have just a director and a tutoring staff.

\section{Hiring an Assistant Director}

To begin the process, the director will confer with the human resources department in order to understand all posting and hiring policies. After consulting with that department, the director or a hiring committee will create a job description to be advertised. The university or college's human resource department can be helpful in posting the position to the institution's website and in submitting it to professional journals and organizations. The position might also be posted to the QMaSC's own website and to quantitative reasoning list-servers. It may also be helpful to forward the announcement to departments served by the QMaSC. Once the director or hiring committee has selected applicants who will be interviewed, the director or hiring committee should have a set of questions that they will ask of all applicants being interviewed. There should also be a timeline

Suggested Citation: Christine Tinsley (2016), "Staffing and Hiring", http://dx.doi.org/10.5038/ 9780977674435.ch13 in G. Coulombe, M. O'Neill, M. Schuckers (Eds.) A Handbook for Directors of Quantitative and Mathematical Support Centers, Neck Quill Press, http://scholarcommons.usf.edu/qmasc_handbook.

This material is based upon work supported, in part, by the National Science Foundation under Grant DUE1255945. Any opinions, findings, and conclusions or recommendations expressed in this material are those of the author(s) and do not necessarily reflect the views of the National Science Foundation 
with dates for interviews, for making the first offer, for making a second offer (if necessary), and for notifying other applicants that the position has been filled. Some possible interview questions are:

1. What do you already know about our institution and our students?

2. Tell me about yourself as a tutor, as a supervisor, and as a coworker.

3. How do you handle correcting a staff member?

4. How do you wish to be corrected?

5. How would you handle a difficult student?

6. With respect to instruction or training, what are your strengths?

7. What qualities do you wish to develop through this position?

8. In working with faculty to develop quantitative material, what specialization can you offer?

9. How will this position fit into your career trajectory?

10. Where do you see yourself in five years?

11. Do you have questions for me (us)?

At the end of the interview, the interviewer will let the applicant know when the search will culminate in a hiring decision.

Normally, the director will make a formal offer of the position to the top applicant. (If the offer is not accepted, the offer will go to the second applicant, etc.) After one of the applicants has accepted the offer of the position, the director will follow up with all other applicants thanking them for their applications (and, if interviewed, for their time), letting them know that despite their strong applications, the position has been filled.

In some institutions, the human resources department or the home department provides training in FERPA [1], sexual harassment, and academic misconduct. If the human resources department does not provide this training, the director should provide or arrange training in these areas. Once the employee has finished all training, he or she should sign a letter (see appendix "Acknowledgement of Policies") recognizing that she or he understands the institution's policies concerning these matters.

\section{Hiring Graduate Teaching Assistants}

Larger institutions might hire graduate teaching assistants to staff the QMaSC. Consult with the human resources department or graduate program to find out what policies need to be followed to employ teaching assistants as tutors or staff in the QMaSC. Whether or not these employees need to be hired, the director still needs to make sure they have completed the sexual harassment, FERPA, academic misconduct, or other training that is required by the institution's human 
resources department. If the human resources department or graduate school does not provide training in sexual harassment, FERPA, or academic misconduct, the director should provide the employee with training in these areas. Once the employee has finished all training, have the employee sign a letter, (see appendix "Acknowledgement of Policies") recognizing that she or he understands the institution's policies concerning these matters. Depending on the institution and the teaching assistants themselves, teaching assistants may need coaching or training in order to be effective tutors. A separate training program can be designed for them, or they can be included in training activities with the student peer tutors.

\section{Hiring Professional Tutors}

As with the Assistant Director position, the director begins by consulting the human resources department in order to understand all posting and hiring policies. Most of the discussion about hiring an assistant director can apply to hiring professional tutors. Qualified applicants should have a demonstrated proficiency in math (or the content that they will tutor), strong interpersonal and communication skills (able to work with individual students or with small groups of students), and good employee skills (submitting documents in a timely fashion and responding to email promptly). In addition to tutoring and encouraging students as they learn content, the tutor should teach students good study skills that can help them to become independent learners, so interviewers should seek to find out what the prospective tutor knows about teaching study skills and about different types of learners.

\section{$5 \quad$ Hiring Student Tutors}

Many QMaSCs have each potential tutor submit an application, a copy of his or her transcript, and, if he or she has one, a résumé. (See the "Sample Application" in the appendix.) If names of potential tutors come from departments that have vetted the potential tutors, then the students' abilities with the material content have been verified. If a student who has not been vetted through a department applies to become a tutor, he or she should be asked to provide the names of two professors who can verify the student's proficiency with the material. In both cases, it can be helpful to ask a student to provide the name of a faculty or staff member outside the department who can provide a reference regarding reliability and interpersonal skills. Some QMaSCs might ask the student to provide a letter of reference as part of his or her application; others might send an email to the student's references asking for verification independently (see the "Quick Reference Request" in the appendix). The QMaSC might also administer a proficiency exam in case further verification of the student's abilities with math (or other topics) is required. Such an exam can 
have distinct levels of math in order to determine the applicant's level of ability (see the "Math Proficiency Questions" in the appendix).

After applications and references have been obtained, an interview can be set up. All applicants should be asked the same questions in the interview so that the director can fairly assess their qualifications. As part of the interview, the applicants can be asked to explain a solution to a particular problem, and they can then be asked to play the role of a tutor coaxing a student to arrive at a solution to a problem. Other questions that can be useful are:

1. What is your attitude about mathematics (or other subject that will be tutored)?

2. You are being considered as a tutor for (course or department): What was your experience in the class?

3. How do you feel about students who have a hard time understanding the material?

4. What would you say to a student who comes in and talks negatively about a professor?

5. How would you handle a student who just wants you to do their homework?

6. What would you do if you were unable to answer a student's questions?

The interview should inform the applicant about expectations of tutors, and it should include a tour of the QMaSC. Tell the applicants about various trainings that will be required of them if they are hired (FERPA, sexual harassment, academic misconduct, tutor training) and about any documents that will be required (social security number, I-9, W-4, direct deposit). When the QMaSC staff or hiring committee has made decisions about which applicants to hire, the hiring letter should outline the expectations and requirements for tutors. Applicants should be asked to sign or initial the letter to indicate that they understand and accept these requiements and expectations. Additionally, once the various trainings are completed, the QMaSC may wish to have the tutor sign a letter recognizing that she or he understands the institution's and QMaSC's policies. 


\section{Appendix}

\section{Acknowledgement of Policies}

\section{Academic Misconduct}

"Academic misconduct is defined as any act which improperly affects the evaluation of a student's academic performance or achievement. It specifically includes cheating, plagiarism, fabrication, fraud, destruction of property, and bribery or intimidation, as well as assisting others or attempting to engage in such acts. It is the responsibility of each student to be familiar with the definitions, policies and procedures concerning academic misconduct; and unfamiliarity with the code alters none of a student's rights or responsibilities thereunder." [2]

\section{Sexual Harassment}

"Sexual Harassment is unlawful and may subject those who engage in it to University sanctions as well as civil and criminal penalties. Since some members of the university community hold positions of authority that may involve the legitimate exercise of power over others, it is their responsibility to be sensitive to that power. The University is committed to providing an environment of study and work free from sexual harassment and to ensuring the accessibility of appropriate grievance procedures for addressing all complaints regarding sexual harassment." [2]

\section{Confidentiality and Privacy}

"Staff members may become aware of personal information concerning students for example grades, personal problems, etc. this information is protected by the Family Educational Rights and Privacy Act (FERPA). Staff members should not discuss this information with other staff members or students. If a student discusses emotional, physical or personal problems you should refer them to the appropriate resources." [2]

I understand and acknowledge the following policies.

Tutor Signature

Date 


\section{Sample Application (University of Oklahoma)}

All applicants need to include: 1) completed application, 2) resume, 3) copy of transcript, and 4) one letter of recommendation from a math professor.

First:

MI: Last:

Local Address:

Phone: Email Address:

Date of Birth: ID Number:

Are you currently enrolled: How many credit hours are you taking:

Status/ Class standing: Sophomore Junior Senior Graduate Student Major: Overall GPA: GPA in Math Courses:

Are you currently employed somewhere else on campus:

If yes, where:

Based on my performance in class or my previous education, I feel competent to tutor students in the following courses/disciplines: Specific Course(s) / Discipline(s):

Education

\begin{tabular}{|l|l|l|}
\hline $\begin{array}{c}\text { Name and Location. Full Address include country if } \\
\text { located outside of the USA }\end{array}$ & Dates attended & $\begin{array}{c}\text { Graduation date and } \\
\text { degree earned }\end{array}$ \\
\hline High School: & & \\
\hline Undergraduate College: & & \\
\hline Graduate School or Other Education: & & \\
\hline
\end{tabular}


Employment History

\begin{tabular}{|l|c|c|}
\hline Position Held or Title & $\begin{array}{c}\text { Dates of } \\
\text { Employment }\end{array}$ & $\begin{array}{c}\text { Employer's Name and Location. Full Address. Include } \\
\text { country if located outside the USA. }\end{array}$ \\
\hline & & \\
\hline & & \\
\hline & & \\
& & \\
& &
\end{tabular}

Professional Reference

Make sure to include a letter of recommendation from a professor

\begin{tabular}{|l|l|}
\hline Name and Title & Contract Information \\
\hline & \\
\hline & \\
\hline
\end{tabular}

Please write a short paragraph discussing what skills you can bring to the position. Include any relevant jobs or past experiences that make you qualified for the position. 


\section{Quick Reference Questions}

Subject: RSVP requested by Friday: 2-minute reference for Student Name

Student Name has listed you as a reference outside of the department for which she has applied to become a tutor. Please help us by answering the two questions:

Does this student possess qualities that would indicate promise as a tutor? (Is she/he approachable, patient, enthusiastic, solid/unflappable, excited about the material, and/or understanding of others' confusion?)

Yes.

No.

I have no basis for evaluating these qualities.

See comments.

Does this student possess qualities that would indicate promise as an employee? (Is she reliable? Is she organized? Is she on time for class, appointments, and meetings? Does she respond quickly and in a timely way to email communication?)

Yes.

No.

I have no basis for evaluating these qualities.

See comments.

Comments:

Thank you for your time! 


\section{Math Proficiency Questions}

Please go step-by-step, using the space below to explain how you would solve the following problems.

1. Find the center and radius of the circle: $x^{2}+y^{2}+8 x-6 y-15=0$

2. Use u-substitution to solve the following problem: $\int \sqrt{x} \sin \left(1+x^{3 / 2}\right) d x$ 
3. Given: $f(x, y)=\ln \left(x^{2}+y^{2}\right)$ find $f_{x}, f_{y}$ and $f_{x y}$

Official Use ONLY

Comments and Notes: 


\section{Bibliography}

[1] U.S. Department of Education, Family Policy Compliance Office, "Family Educational Rights and Privacy Act (FERPA)." http://www.ed.gov/policy/gen/guid/fpco/ferpa/ index.html, 2013

[2] The University of Oklahoma, "OU general catalog." http://catalog.ou.edu,, 2013. 